\title{
Bibliometric Analysis of Atmospheric Simulation Trends in Meteorology and Atmospheric Science Journals: Update
}

\author{
Jinfeng Li
}

\author{
College of Environmental Sciences and Engineering, Peking University, Beijing, 100871, People's Republic of China \\ Author's e-mail address: lijinfeng0514@126.com
}

RECEIVED: September 4, 2017 * REVISED: November 25, 2017 * ACCEPTED: December 1, 2017

THIS PAPER IS DEDICATED TO PROFESSOR LEO KLASINC ON THE OCCASION OF HIS $80^{\text {Th }}$ BIRTHDAY

\begin{abstract}
This study was conceived to evaluate the global scientific output of atmospheric simulation research and to assess the characteristics of research tendencies in the articles from 1990 to 2016. Data were based on the publications in the category of "meteorology \& atmospheric sciences" from the Science Citation Index Expanded database. By synthetic analysis of author keywords, KeyWords Plus, titles and abstracts, it was concluded that the hottest topics in this field were climate, surface, temperature and precipitation; air pollutants of most concern were particulate matter, nitrogen oxides and ozone; emission inventory, sensitivity analysis, satellites, parameterization, schemes, and data assimilation were the most widely used tools in atmospheric modeling. Among the analyzed countries, China has experienced the highest increase in productivity. Due to the challenge of severe air pollution and a series of positive policies including intensive financial input, the atmospheric simulation research in China was very prosperous during the last ten years and its number of articles ranked the second since 2012.
\end{abstract}

Keywords: bibliometrics, meteorology and atmospheric sciences, modeling, simulation, research trends, climate change, particulate matter.

\section{INTRODUCTION}

A TMOSPHERIC simulation is a strong tool to evaluate and predict the variations, causes and influence of meteorological phenomenon and air pollution. Climate change threatens the development of many countries and becomes a big issue in political negotiations. A big progress was made as the threshold for entry into force of the Paris Agreement was achieved on October 52016 and the Paris Agreement entered into force on November 4 2016. As of July 2017, 154 of 195 UNFCCC members have ratified the agreement. ${ }^{[1]}$ However, President Donald Trump declared to withdraw the USA from Paris Agreement on June 1 this year and stopped funding climate change programs which made the target of $2{ }^{\circ} \mathrm{C}$ seem to be hard to achieve again. China is predicted to play a leading role in the global reduction of greenhouse gases emissions instead of the USA afterwards.

On the other hand, severe haze and photochemical smog attract more and more attention in developing countries, such as China and India. After the release of air quality data from U.S. Embassy in Beijing in 2008, the public in China started to realize the harm of $\mathrm{PM}_{2.5}$ and the government invested tens of billions of dollar to the prevention and control of air pollution, including scientific research to identify the emission sources, routine monitoring, legal regulations and industrial upgrading. New ambient air quality standards (GB3095-2012) was put into force in 2016 with $\mathrm{PM}_{2.5}$ and $\mathrm{O}_{3}$ included for the first time and stricter $\mathrm{PM}_{10}$ and $\mathrm{NO}_{2}$ standards. The annual $\mathrm{PM}_{2.5}$ concentrations in Beijing kept a declining trend from $89.5 \mu \mathrm{g} \mathrm{m}^{-3}$ in 2013 to $73 \mu \mathrm{g} \mathrm{m}^{-3}$ in 2016. ${ }^{[2]}$ It's still beyond the national standard of $35 \mathrm{\mu g} \mathrm{m}^{-3}$ and the standard of $10 \mu \mathrm{g} \mathrm{m}^{-3}$ recommended by World Health Organization (WHO). ${ }^{[3]}$

Research trends on atmospheric simulation until 2007 was analyzed with bibliometric methods using "model*" and "simulat*" as search keys in the category of meteorology \& atmospheric sciences in the Science Citation Index Expanded (SCI-EXPANDED) database. ${ }^{[4]}$ Here we update these results with an analysis of data till end of year 2016 and improved searching methods. 


\section{DATA SOURCES AND METHODOLOGY}

The data during 1972-2016 were from the online version of SCI-EXPANDED, Web of Science. "Model*" and "simulat*" were used as search keys in the category of meteorology \& atmospheric sciences, which included 85 journals according to the Journal Citation Reports (JCR) in 2016. The word "model*" might stand for "model", "models", "modeling", and "modelling", while "simulat" might represent "simulate", "simulation", and "simulating".

Searching methods were improved in two aspects in this paper. First, in last paper, ${ }^{[4]} 51$ journals in the category of meteorology \& atmospheric sciences were used as search keys to facilitate downloading of the data, while this time the papers in this category were refined directly in the database. Second, in last paper, ${ }^{[4]}$ most-frequently used words were used as search keys in the titles, author keywords and Keywords Plus, while in this paper abstracts were also concluded.

Hot topics in the aspects of simulated items related to meteorology and air pollution, types of variation and research methods were identified based on their occurrences in the author keywords and Keywords Plus. These words were used as search keys in the titles, abstracts, author keywords and KeyWords Plus in the SCI-EXPANDED database to depict their developing trends from 1990 to 2016.

Articles originating from England, Scotland, Northern Ireland, and Wales were reclassified as from the United Kingdom (UK). Articles from Hong Kong were included in China.

In the total 112144 publications during 1990-2016, the article was the most frequently used document type with $97 \%$ of total publications. As journal articles represented the majority of peer-reviewed document types and original findings within this field, only the 109129 articles were used for further analysis in this study.

\section{RESULTS AND DISCUSSION}

\section{Characteristics of Publication Outputs}

Atmospheric simulation research developed rapidly after 1990, from 624 articles in 1990 to 7942 articles in 2016. The cumulative number of articles from 1972 to 2016 is shown in Figure 1. The growth pattern was simulated by three exponential regressions:

$$
\begin{aligned}
& 1972-1989: P=74.64 Y^{1.38}, R^{2}=0.9929, \\
& 1990-2007: P=0.16 Y^{3.58}, R^{2}=0.9948, \\
& 2008-2016: P=0.54 Y^{3.22}, R^{2}=0.9997 .
\end{aligned}
$$

From the third formula, it was predicted that the number of articles published in 2017 would reach about 8344.

In this study, the number of articles during 19922007 was larger than that in previous study. ${ }^{[4]}$ Take the year 1992 as an example, the number of articles was 834 when the data was searched in 2008, and it increased to 1478 now. This is because SCI-EXPANDED is a developing dynamic database. The number of journals in each category was increasing year by year (Figure 2). The category of meteorology \& atmospheric sciences included 51 journals in 2007 and 85 journals in 2016. Therefore, the articles in some journals were added in 1992, including Aerosol Science and Technology, Indian Journal of Radio \& Space Physics, Journal of Applied Meteorology, Journal of Atmospheric and Terrestrial Physics, Journal of Atmospheric Chemistry, and Journal of Geophysical Research-Atmospheres.

After the expansion of this category, Journal of Geophysical Research-Atmospheres replaced Atmospheric Environment $(A E)$ as the flagship journal of this particular research field, with 12059 articles in total (11.05\%) during 1990-2016, followed by Atmospheric Environment (6642, $6.09 \%)$, Journal of Climate (6089, $5.58 \%$ ), and Atmospheric Chemistry and Physics (5214, $4.78 \%$ ).

Another reason is that some journal names changed in SCI-EXPANDED. For instance, Atmospheric Environment was named as Atmospheric Environment Part A-General Topics and Atmospheric Environment B-Urban Atmosphere during 1992-1993, and the name of Meteorological Magazine used to be Meteorologische Zeitschrift during 19921999.

In previous study, 51 journals were used as search keys so some articles were lost. This time we refined the

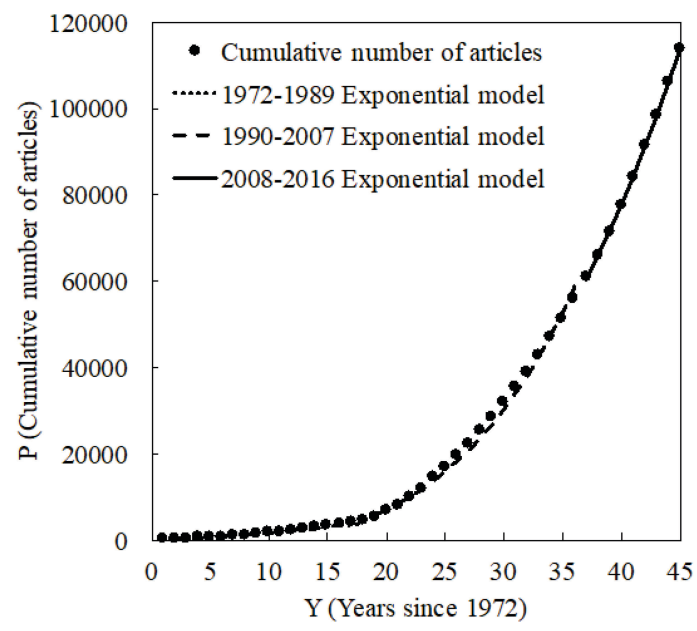

Figure 1. Cumulative number of articles by year during 1972-2016. 
searching by the name of the category "meteorology\& atmospheric sciences" in SCI-EXPANDED database directly, so the results were more accurate.

However, as we mentioned in last paper, ${ }^{[4]}$ some articles on atmospheric simulation might have been published in journals in the categories of environmental sciences and multidisciplinary geosciences. Thus the absolute article numbers shown here did not reflect the true situation in terms of all atmospheric simulation articles, but estimates of research trends in these papers were probably not far from the real situation.

The leading countries/territories in atmospheric simulation research were the USA $(48487,44.43 \%)$, the UK (11973, 10.97\%), Germany (11765, 10.78\%), China (10139,

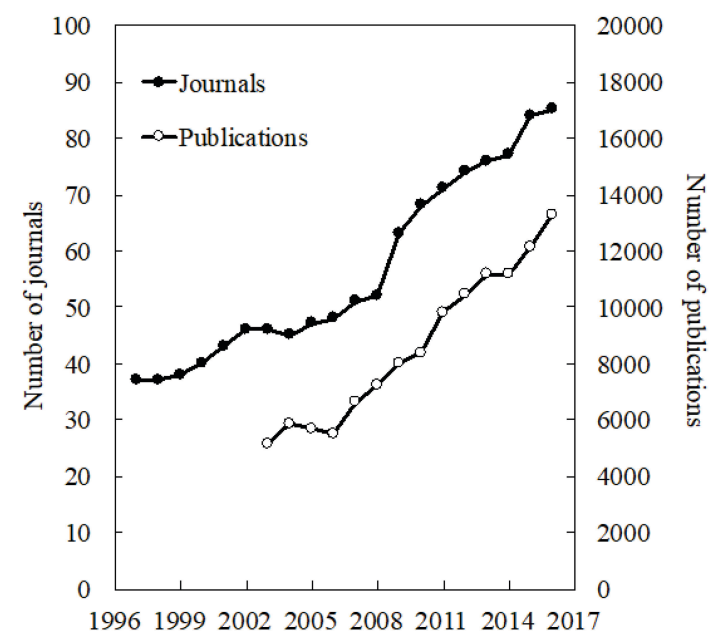

Figure 2. The number of journals and publications in the category of meteorology \& atmospheric sciences during 1997-2016.

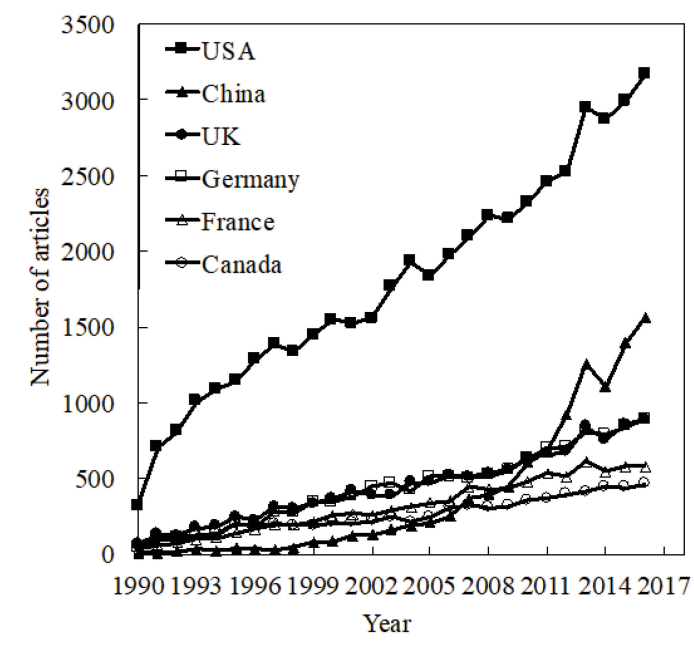

Figure 3. Comparison of growth trends of the top six productive countries during 1990-2016.
$9.29 \%)$, France (8425, $7.72 \%)$, and Canada (6832, $6.26 \%)$. The performance of China was remarkable. Its research started late compared with other countries, however, the number of publications started to rocket up since 1999 and quickly surpassed that of the UK, Germany, France and Canada, and became the second productive country after 2012 (Figure 3).

From the publications of organizations, we can also see how fast China developed. The institutes contributed most to this area were National Oceanic and Atmospheric Administration (7466, $6.84 \%$ ), National Aeronautics and Space Administration (7112, $6.52 \%)$, National Center for Atmospheric Research (5458, $5.00 \%$ ), University of California System (4194, $3.84 \%$ ), and Chinese Academy of Sciences (3866, $3.54 \%$ ) during 1990-2016. All the top four organizations were from the USA. Whereas, Chinese Academy of Sciences became the top one productive institute since 2014 and published 561 articles (7.06 \%) in this field in 2016.

\section{Analysis of Research Trends}

Research trends in atmospheric simulations were separated into four categories - simulated items related to meteorology, air pollutants, types of variation and research methods. The words listed in Figures 4-7 all include their plural forms, abbreviations, and other transformations, as well as words with similar meanings. These words were used as search keys in the topic in SCI-EXPANDED database, which means they were searched in titles, abstracts, author keywords and Keywords Plus of all publications.

Climate, surface, temperature and precipitation were the most popular simulated items related to meteorology (Figure 4). The research in climate showed the fastest increasing speed and quickly surpassed that in surface and temperature. Surface and temperature were highly linked two words as sea/ocean and land surface temperature were all important indicators to show climate patterns and the influence of greenhouse gases to the lands, glaciers and ecosystems. Similar to the results in bibliometric studies on climate change, ${ }^{[5]}$ this study also indicated that temperature and precipitation would be the focus of climate change research. Wind is another hot topic in atmospheric simulation research. Its measurements and accurate simulation could benefit the evaluation and exploitation of wind energy resources. ${ }^{[6]}$

Referring to the trends of air pollutants (Figure 5), "particulate matter" had a distinctly higher incidence, being mentioned in 22736 articles. It's a common problem all over the world now. As WHO reported in 2016, ${ }^{77]}$ according to the measurement data in 3000 cities of 103 countries, $84 \%$ of the assessed population breathed the air with $\mathrm{PM}_{10}$ and $\mathrm{PM}_{2.5}$ concentrations higher than the annual mean levels recommended by WHO ( $30 \mu \mathrm{g} \mathrm{m}^{-3}$ for $\mathrm{PM}_{10}$ and $10 \mu \mathrm{g} \mathrm{m}^{-3}$ 
for $\mathrm{PM}_{2.5}$ ). High concentrations of particulate matter increased the risk of stroke, heart disease, lung cancer, and chronic and acute respiratory diseases, including asthma.

Besides particulate matter, ozone was another important pollutant that drew more and more attention. Take Shanghai as an example, although the concentrations of $\mathrm{PM}_{10}$ and $\mathrm{PM}_{2.5}$ decreased dramatically by $14.5 \%$ and $15.1 \%$, ozone concentrations still increased by $1.9 \%$ in 2016. ${ }^{[8]}$ Moreover, ozone was the dominant pollutant in $30.8 \%$ of 74 cities in China in 2016. ${ }^{[8]}$ More research on chemical mechanisms, emissions and source apportionment were needed to guide the control strategies on ozone. As the precursors of ozone, nitrogen oxides and volatile organic compounds also showed an increasing trend in the number of articles.

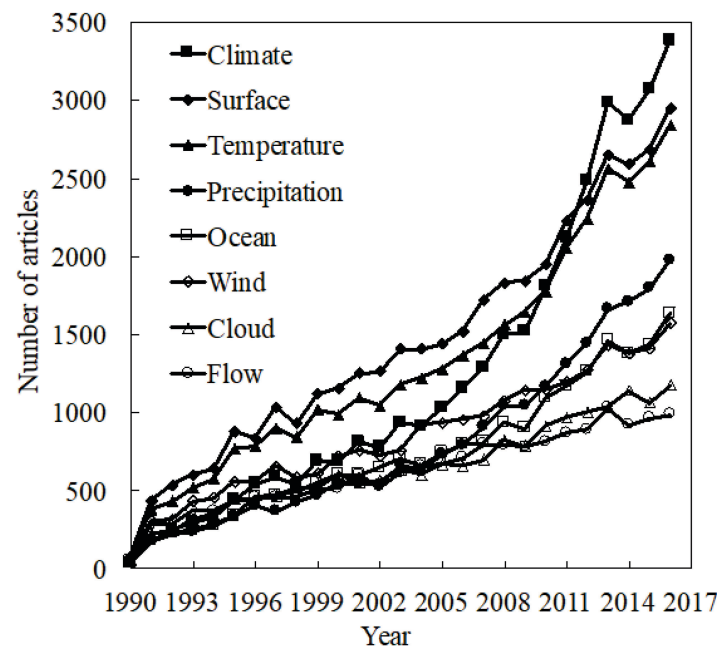

Figure 4. Comparison of the trends of simulated items related to meteorology during 1990-2016.

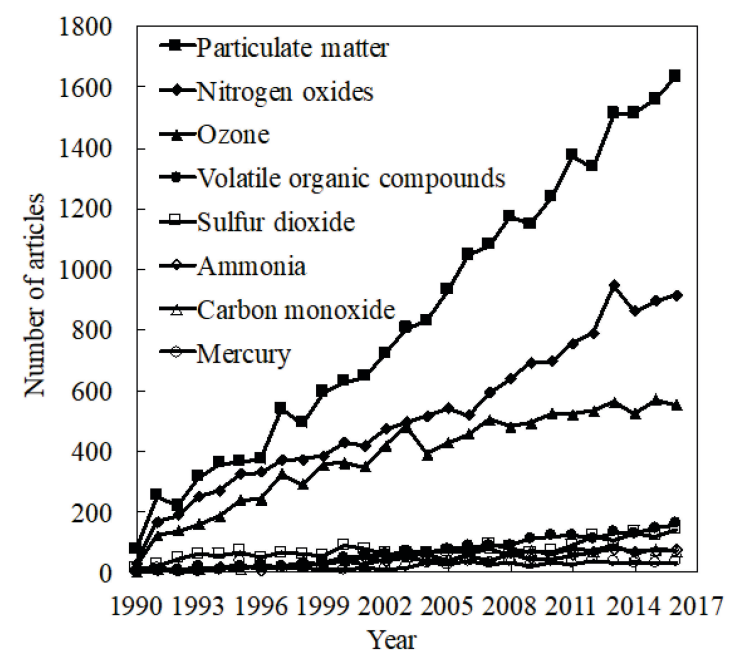

Figure 5. Comparison of the trends of air pollutants during 1990-2016.
The interaction between climate and air pollution and among pollutants was also a hot topic. Extreme weather due to climate change, such as high temperatures would benefit the formation of ozone. Anthropogenic emissions produced higher concentrations of black carbon, which absorbed the sun radiation and had the effect of cooling which weakened photochemical reactions to form ozone. Recent research revealed that the fast formation of sulfate due to the reaction of $\mathrm{SO}_{2}$ and $\mathrm{NO}_{2}$ in aerosol water in the high neutralizing environment was the main reason for the severe haze spreading Northern China in winter. ${ }^{[9]}$

As for the types of variation, climate variability, dynamics and circulation were the top three hot issues (Figure 6). Attention should be paid on emission, the number of which quickly surpassed that of convection and transport after 2013. Different from sulfur dioxide and nitrogen oxides which were directly emitted from sources, ozone and a part of particulate matter were formed through chemical reactions in the atmosphere and harder to be precisely simulated. Moreover, fine particulate matter and volatile organic compounds came from various sources, thus thorough and precise emission inventory was vital to the accurate simulation of the formation and transport of air pollutants as well as source apportionment. Unlike the USA and European Union, China still did not establish the national emission inventory for $\mathrm{PM}_{10}, \mathrm{PM}_{2.5}$ or volatile organic compounds, which hampered effect control of these pollutants. In August 2013, the Ministry of Environment Protection initiated Clean Air Action Plan and started to prepare the national emission inventory. Therefore, emission inventory will continue to be a research hotspot in the near future.

Atmospheric models were evaluated and validated with measurement data, from ground observations and remote sensing (including satellites). Satellite data were used

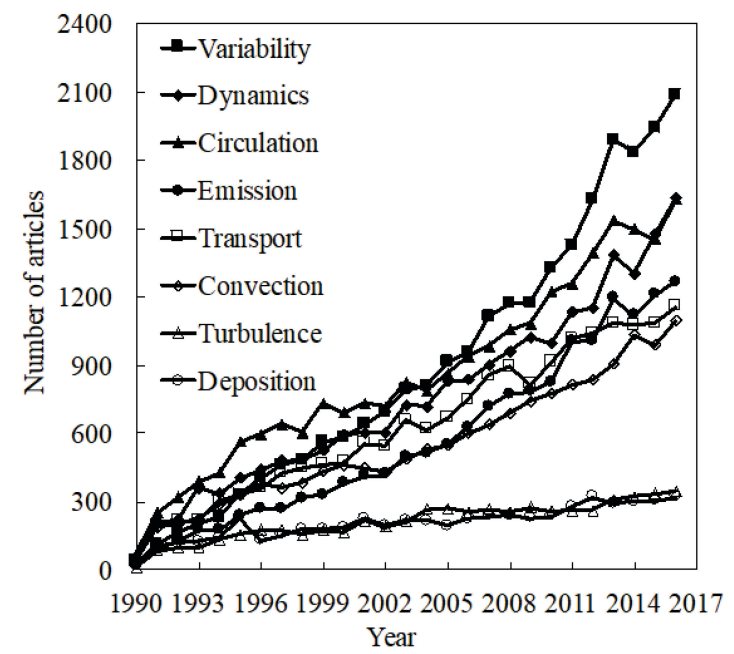

Figure 6. Comparison of the trends of types of variation during 1990-2016. 
to derive global variations of precipitation, ${ }^{[10]}$ terrestrial ecosystem production, ${ }^{[11]}$ tropospheric aerosol optical thickness, ${ }^{[12]}$ and oceanic primary production. ${ }^{[13]}$ Data assimilation was an important way to improve the performance of models.

Parameterization and schemes are basic elements of atmospheric models, such as a comprehensive mass flux scheme for cumulus parameterization in large-scale models, ${ }^{[14]}$ a two-moment cloud microphysics scheme for a general circulation model[15] and a size-segregated particle dry deposition scheme for an atmospheric aerosol module. ${ }^{[16]}$ Sensitivity analysis was widely used to test the influence of different emission sources and parameters.

\section{CONCLUSION}

In this study, 109129 articles on atmospheric simulation research were obtained from SCI-EXPANDED database during 1990-2016. New findings since the last bibliometric studies on atmospheric simulation research during 19922007 include that Journal of Geophysical ResearchAtmospheres replaced Atmospheric Environment (AE) as the flagship journal of this particular research field; the atmospheric simulation research in China boomed during the last ten years. The number of articles from China ranked the second during 2012-2016 and the number of articles from Chinese Academy of Sciences surpassed that of some traditional strong research organizations in the USA in 2014 and kept the leading position till 2016.

By synthetically analyzing the changes of research hotspots in author keywords, KeyWords Plus, words in publication titles and abstracts, the development trend of atmospheric simulation research was predicted. It can be

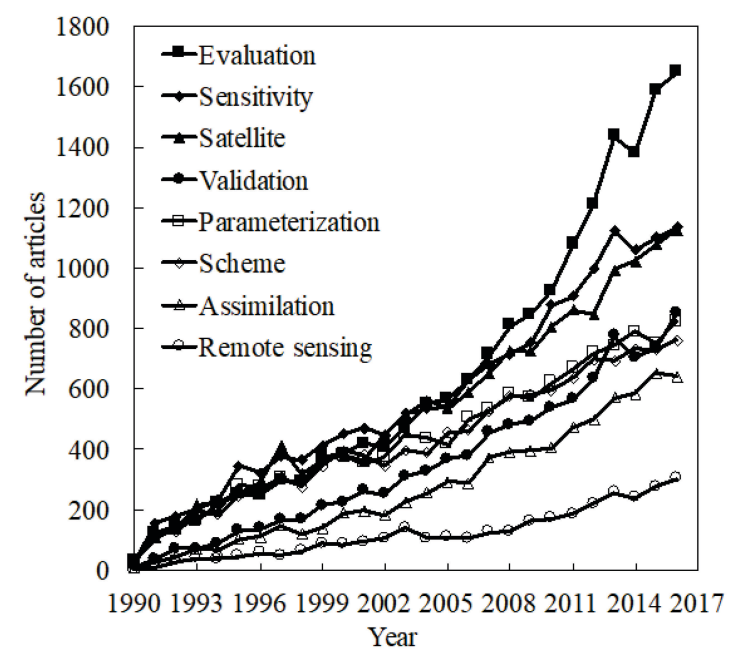

Figure 7. Comparison of the trends of research methods during 1990-2016. concluded that climate, surface, temperature and precipitation are the topics of most concern; particular matter, nitrogen oxides and ozone still need intensive studies. Relating to these air pollutants, emission inventory and sensitivity analysis will continue to be the focus of atmospheric simulation research in the near future. Satellites, parameterization, schemes and data assimilation are the predominant research methods applied in the development of atmospheric modeling.

\section{REFERENCES}

[1] United Nations Framework Convention on Climate Change. Paris Agreement - Status of Ratification. http://unfccc.int/paris_agreement/items/9444.php, 21 July 2017.

[2] Beijing Municipal Environmental Protection Bureau. Beijing Environmental Statement 2013-2016. http://www.bjepb.gov.cn/bjhrb/xxgk/ywdt/hjzlzk/h jzkgb65/index.html.

[3] World Health Organization. Air quality guidelines: Global update 2005. Copenhagen: WHO Regional Office for Europe. 2006.

[4] J. F. Li, Y. H. Zhang, X. S. Wang, Y. S. Ho, Croat. Chem. Acta 2009, 82, 695.

[5] J. F. Li, M. H. Wang, Y. S. Ho, Global Planet. Change 2011, 77, 13.

[6] C. L. Archer, M. Z. Jacobson, J. Geophys. Res. 2003, $108,4289$.

[7] World Health Organization. Ambient air pollution: A global assessment of exposure and burden of disease. Copenhagen: WHO Regional Office for Europe. 2016.

[8] Ministry of Environmental Protection of the People's Republic of China. China Environmental Statement 2016.

http://www.zhb.gov.cn/hjzl/zghjzkgb/lnzghjzkgb/.

[9] Y. Cheng, G. Zheng, C. Wei, Q. Mu, B. Zheng, Z. Wang, M. Gao, Q. Zhang, K. He, G. Carmichael, U. Pöschl, H. Su, Sci. Adv. 2016, 2, e1601530.

[10] P. P. Xie, P. A. Arkin, B. Am. Meteorol. Soc. 1997, 78, 2539.

[11] C. S. Potter, J. T. Randerson, C. B. Field, Global Biogeochem. Cy. 1993, 7, 811.

[12] M. Chin, P. Ginoux, S. Kinne, O. Torres, B. N. Holben, B. N. Duncan, R. V. Martin, J. A. Logan, A. Higurashi, T. Nakajima, J. Atmos. Sci. 2002, 59, 461.

[13] D. Antoine, J. André, A. Morel, Global Biogeochem. Cy. 1996, 10, 57.

[14] M. Tiedtke, Mon. Weather Rev. 1989, 117, 1779.

[15] A. Gettelman, H. Morrison, S. J. Ghan, J. Climate 2008, 21, 3660.

[16] L. Zhang, S. Gong, J. Padro, L. Barrie, Atmos. Environ. 2001, 35, 549. 